\title{
ANALYSIS OF VARIABILITY, HERITABILITY AND GENETIC ADVANCE FOR YIELD AND YIELD RELATED TRAIT IN WHEAT (TRITICUM AESTIVUM L.) GENOTYPES
}

\author{
ANUJ KUMAR ${ }^{1}$, SHAILENDRA SINGH GAURAV ${ }^{2}$, DEEPAK KUMAR BAHUGUNA ${ }^{3}$, \\ PRIYANKA SHARMA ${ }^{4}$, TEJBIR SINGH ${ }^{5} \&$ POORAN CHAND ${ }^{6}$ \\ ${ }^{1}$ Research Scholar, Department of Genetics and Plant Breeding, Chaudhary
}

Charan Singh University, Meerut, Uttar Pradesh, India

${ }^{2}$ Department of Genetics and Plant Breeding, Chaudhary Charan Singh University, Meerut, Uttar Pradesh, India

${ }^{3}$ Department of Seed Science and Technology, Chaudhary Charan Singh University, Meerut, Uttar Pradesh, India

${ }^{4}$ Department of Biotechnology, Chaudhary Charan Singh University, Meerut, Uttar Pradesh, India

${ }^{5}$ Department of Genetics and Plant Breeding, Kisan PG College, Simbhaoli, Hapur, India

${ }^{6}$ Department of Genetics and Plant Breeding Sardar Vallambhai Patel University of

Agriculture and Technology, Meerut, Uttar Pradesh, India

\begin{abstract}
Estimation of the variability, heritability and genetic advance in the wheat genotypes (Triticum aestivum L.) is most important in the plant breeding because, with the help of this study the plant breeder developed a new and improved variety of wheat. Thirty wheat genotypes were evaluated at the Research Farm of Department, of Genetics \& Plant Breeding, Chaudhary Charan Singh University, Meerut U. P. (India), during rabi seasons of 2014-2015 in a randomized block design with three replications for the estimation of the analysis of variance, heritability and genetic advance. The result shows, all the genotypes are highly significant at $0.05 \%$ probability level in analysis of variance. In variability analysis the genotypic coefficient of variation were high for grain yield (26.05), biological yield (20.80), flag leaf area (19.70), number of productive tillers (16.47) and number of grains per spike (16.30), while the estimates of phenotypic coefficient of variation were high for grain yield (27.64), biological yield (21.88), flage leaf area (19.98), number of productive tillers (17.32) and number of grains per spike (16.86). Heritability estimates were highest for The Days to 50\% flowering (85.96), number of productive tillers (90.50), flage leaf area (97.27), chlorophyll content (87.57), grain yield (88.84) and biological yield (90.39), and the Genetic advance estimates were highest for Flag leaf area(17.48), No. Of grains per spike (14.00) and Plant height (11.64). In the present study, result based on high variability and high heritability coupled with high genetic advance for interesting traits can be used for further improvements of yields and its related traits, through ideal breeding scheme.

KEYWORDS: Wheat, Analysis of Variance, Variability, Heritability and Genetic Advance
\end{abstract}

Received: Jul 11, 2017; Accepted: Jul 28, 2017; Published: Aug 01, 2017; Paper Id.: IJASRAUG201775

\section{INTRODUCTION}

All over the world, wheat has an important place in nourishment of people. It is an important cereal crop and staple food, for world population. Wheat is a crop of global significance, grown in diversified environments (Baranwal et al, 2012). Wheat consumed in various forms, by the population such as bread, chapatti, porridge, flour, suji etc. In cereal crop, grain yield is the complex quantitative characters, which is an incentive by a 
numerous yield contributing characters. These character influence grain production, both directly and indirectly, and the breeder is naturally interested in investigating the extent and type of association of such traits ( Zafarnaderi et $a l, 2013)^{[2]}$. The study of genetic variability reveals about the presence of variation in their genetic constitution and provides the basis for effective selection. Reduction in the genetic variability makes the crops increasingly vulnerable to diseases and adverse climatic changes (Аremu, 2012) ${ }^{[3]}$. Therefore, the information about degree of genetic variability and divergence present in wheat help in selecting the parents for evolving superior varieties. In successful breeding program, genetic variability play a vital role, as we know the plant with more diversity or variability has the greater chance of exploiting, to generate productive recombination and the broad sense variability in segregating generation during genetic improvement. Hence, heritability estimates in this study, which would help to predict about the possible progress that can be attained by making the selection process effective. Moreover, genetic advance estimates give a clear picture of segregating generations, to make selection effective (Saleem et al, 2016) ${ }^{[4]}$.

The assessment of heritability provides the information about the particular character, which can be transmitted from one generation to the next generation. Knowledge of heritability of a trait guides a plant breeder to predict behaviour of succeeding generations and helps to predict the response to selection. Heritability values can be used as a measuring scale, to determine genetic relationship between parents and progeny (Memon et al, 2007) ${ }^{[5]}$. Heritability and genetic advance enables the breeders to use best genetic stock, for improving the crop (Mangi et al, 2008) ${ }^{[6]}$. High genetic advance coupled with high heritability estimates offer a most suitable condition for selection. The success of any breeding programme, depends upon the amount of genetic diversity, existing in germplasm and it is a prerequisite to have a good knowledge of heritability and genetic advance, present in different yield associated parameters (Waqar-ul Haq et al, 2008) ${ }^{[7]}$. This study is aimed to estimate variability and genetic parameters, for yield and other agronomic characters. These values will help in making effective selection for the improvement of characters under study.

\section{MATERIALS AND METHODS}

Thirty wheat genotypes were evaluated for variability, heritability and genetic advance, for eleven yield contributing traits in bread wheat (Triticum aestivum L.). The experiment was conducted at the research farm, Department of Genetics \& Plant Breeding, Chaudhary Charan Singh University, the experimental material for the present study consisted of 30 morphologically diverse genotypes viz, 101HP-1633, 102HP-1731, 103HP-1744, 105HPW-42, HPW-89, HPW-147, HPW-155, HPW-184, HPW-251, GW-322, AKW-1071, 49GW-273, 8C-306, 48GW-190, 9BW-11, 47GW173, VL-404, 46GW-120, HD-2967, 45GW-89, 91HI-1077, 44GW-18, 92HI-1418, 43GW-10, 93HI-1464, 2AJANTA, 94HI-1500, AKW-381, 95HI-1531. They were evaluated in randomized block design with three replications. In this experiment, row-to-row and plant-to-plant distances were kept at $25 \mathrm{~cm}$ and $10 \mathrm{~cm}$, respectively. Standard agronomic practices were adopted in each experiment to raise a good crop. Observation were recorded at maturity, taken 5 randomly 5 plant from each genotype in each replication for various quantitative characters $v i z$, Plant height, Days to flowering, Days to maturity, Number of productive tillers per plant, Number of spikelets per spike, Flag leaf area, Chlorophyll contents, Biological yield, Harvest index (\%),1000-grain weight and Grain Yield per plant.

\section{Statistical Analysis}

The following statistical analysis were carried out using the mean values of the individual genotypes, at the $0.05 \%$ of probability level 
Recorded data were subjected to the statistical analysis, to calculate analysis of variances at $0.05 \%$ of probability level (ANOVA). Analysis of variance was performed by using the statistical software SPSS version 16.0 (SPSS, Chicago, USA) program, variability, heritability $\left(\mathrm{h}^{2}\right)$ is suggested by Hanson, 1995 $5^{[8]}$ and genetic advance was estimated by Johnson, $1995^{[9]}$.

\section{RESULTS AND DISCUSSIONS}

\section{Physiological Traits Analysis}

The results of analysis of variance of the random block design experiment, including a total of 30 Genotypes of wheat in three replications were conducted for 11 different characters. The mean squares for the different sources of variations are presented in Table 1 . The mean squares due to treatment for all the traits were highly significant at $0.05 \%$ probability level, thereby suggesting the presence of considerable amount of variability among the thirty wheat genotypes, with respect to the traits studied under the present investigation. Similarly, Abinasa $(2011)^{[10]}$ reported, highly significant differences among durum wheat genotypes, for plant height, spike length, spikilets per spike, thousand grain weight, biomass yield, grain yield days to heading, days to maturity, number of productive tillers per plant and harvest index. Alam et al. $(2013)^{[11]}$ reported significant differences for grains per spike, 1000 grain weight, plant height and grain yield among fifteen durum wheat genotypes.

Table 1: Physiological Traits Analysis for 30 Wheat Genotypes Evaluated in Randomized Block Design

\begin{tabular}{|l|c|c|c|}
\hline \multirow{2}{*}{\multicolumn{1}{|c|}{ Characters }} & \multicolumn{3}{c|}{ Mean Sum of Squares } \\
\cline { 2 - 4 } & Replication & Treatment & Error \\
\hline d.f & 2 & 29 & 58 \\
\hline Days 50\% flowering & 0.23 & $18.77^{* *}$ & 0.97 \\
\hline No of productive tillers & 0.62 & $4.88^{* *}$ & 0.17 \\
\hline Flag leaf area (cm2) & 3.87 & $224.06^{* *}$ & 2.08 \\
\hline Plant height(cm) & 15.37 & $146.02^{* *}$ & 15.67 \\
\hline Spike (cm) & 0.04 & $2.58^{* *}$ & 0.33 \\
\hline No of spikelets per spike & 0.15 & $4.72^{* *}$ & 0.83 \\
\hline No. of grain per spike & 1.41 & $151.79 * *$ & 3.46 \\
\hline Chlorophyll content $\left(\mathrm{mg} \mathrm{m}^{-2}\right)$ & 0.70 & $64.63 * *$ & 2.92 \\
\hline 1000 grain weight $(\mathrm{g})$ & 12.54 & $46.32^{* *}$ & 6.36 \\
\hline $\begin{array}{l}\text { Grain yield } \\
\text { (g/plant) }\end{array}$ & 0.08 & $18.94 * *$ & 0.76 \\
\hline
\end{tabular}

$* *=$ significant at 0.05 probability level,

\section{Variability}

Genetic variability is the tendency of individuals in a population, to vary from one another. Variability is different from genetic variation, which is the actual amount of phenotypic variation seen in a particular population. Genetic variability in a population is very important because, without variability, it becomes difficult for a population to adapt to environmental changes and plays a very important role in any crop breeding programme. Statistically, the total variability is expressed in terms of phenotypic coefficient of variation (PCV) and the genotypic variability is expressed in terms of genotypic coefficient of variation (GCV). The estimates of mean, range, phenotypic coefficient of variation, heritability and expected genetic advance for 11 traits of 30 wheat genotypes are presented in Table 2 . The estimates of means showed wide range of values, for the thirty genotypes of wheat for all the characters. 
Table 2: Mean, Range, PCV and GCV of Eleven Quantitative Traits of 30 Bread Wheat Genotypes

\begin{tabular}{|l|c|c|c|c|}
\hline \multicolumn{1}{|c|}{ Characters } & Mean & Range & PCV (\%) & GCV (\%) \\
\hline Days 50\% flowering & 86.30 & $82.33-92.00$ & 3.04 & 2.82 \\
\hline No of productive tillers & 7.61 & $5.47-10.57$ & 17.32 & 16.47 \\
\hline Flag leaf area (cm2) & 43.66 & $32.52-71.08$ & 19.98 & 19.70 \\
\hline Plant height(cm) & 83.28 & $69.07-100$ & 9.23 & 7.92 \\
\hline Spike length(cm) & 11.46 & $8.89-13.44$ & 9.07 & 7.56 \\
\hline No of spikelets per spike & 19.69 & $17.40-21.80$ & 7.41 & 5.78 \\
\hline No. of grain per spike & 43.14 & $31.00-61.00$ & 16.86 & 16.30 \\
\hline $\begin{array}{l}\text { Chlorophyll content(mg } \\
\text { m } \text { ) }\end{array}$ & 44.58 & $31.73-52.00$ & 10.87 & 10.17 \\
\hline 1000 grain weight (g) & 40.81 & $32.17-47.85$ & 10.87 & 8.94 \\
\hline $\begin{array}{l}\text { Grain yield } \\
\text { (g/plant) }\end{array}$ & 9.45 & $4.03-15.39$ & 27.64 & 26.05 \\
\hline \begin{tabular}{l} 
Biological yield per plant \\
\hline
\end{tabular} & 18.23 & $10.72-27.45$ & 21.88 & 20.80 \\
\hline
\end{tabular}

Phenotypic coefficient of variation (PCV); genotypic coefficient of variation (GCV).

The estimates of genotypic coefficient of variation were high for many traits such as, duration from grain yield, biological yield, flage leaf area, number of productive tillers and number of grains per spike, while the estimates of phenotypic coefficient of variation were high, for many traits such as, duration from grain yield, biological yield, flage leaf area, number of productive tillers and number of grains per spike. The chlorophyll content showed moderate genotypic coefficient of variation, while the phenotypic coefficient of variation for chlorophyll content and 1000 grain weight phenotypic coefficient of variation.

The Days to $50 \%$ flowering, plant height, spike length, number of spikelet per year, 1000 grain weight showed low genotypic coefficient of variation, while The Days to $50 \%$ flowering, plant height, spike length and number of spikelet per year showed low phenotypic coefficient of variation. Suggested that, adequate variability is present for these traits and hence, there is a scope for employing suitable breeding programs for bringing about improvement in these traits. Similarly research was carried out by Kyosev et al, 2015 ${ }^{[12]}$ and studied the genetic variability of yield, and the phenotypic coefficient of variation (PCV) were higher than genotypic coefficient of variation (GCV), for all the traits. High PCV and GCV were observed in trait grain weight per spike $(\mathrm{PCV}=30.36 \%, \mathrm{GCV}=24.93 \%)$.

Wolde et al,2016 ${ }^{[13]}$ studied sixty eight durum wheat genotypes and observed High PCV and GCV values, which were recorded for productive tillers per plant, number of grains per spike, thousand grain weight, grain yield and harvest index. Wahidy et al, 2016 ${ }^{[14]}$ evaluated twelve, for the estimation of the variability of yield and yield related trait in wheat genotypes and the result that Number of grains /spike, biological yield, harvest index, plant height and number of tillers moderate estimates for PCV \& GCV, Number of grains /spike, flag leaf width, biological yield /plant and harvest index.

\section{Heritability and Genetic Advance}

High PCV or GCV did not provide a clear picture of the extent of genetic gain to be achieved from selection, for the phenotypic traits unless the heritable fraction of the trait was known (kumar et al, 2017) ${ }^{[15]}$. Estimation of heritability is, therefore, important. The knowledge of heritability provides important information to the breeder. 
Table 3: GCV, PCV Heritability and Genetic Advance

\begin{tabular}{|c|c|c|c|c|c|}
\hline & Heritability(Percent) & Genetic Advance & $\begin{array}{l}\text { Genetic Advance } \\
\text { value \% means }\end{array}$ & $\begin{array}{c}\text { Genotypic } \\
\text { Coefficient of } \\
\text { Variations are }\end{array}$ & $\begin{array}{c}\text { Phenotypic } \\
\text { Coefficient of } \\
\text { Variations }\end{array}$ \\
\hline Days of $50 \%$ flowering & 85.96 & 4.65 & 5.39 & 2.82 & 3.04 \\
\hline Number of Productive Tillers & 90.50 & 2.46 & 32.28 & 16.47 & 17.32 \\
\hline Flag leaf area $(\mathrm{cm} 2)$ & 97.27 & 17.48 & 40.03 & 19.70 & 19.98 \\
\hline Plant height $(\mathrm{cm})$ & 73.49 & 11.64 & 13.98 & 7.92 & 9.23 \\
\hline Spike length $(\mathrm{cm})$ & 69.63 & 1.49 & 13.00 & 7.56 & 9.07 \\
\hline No spiklet per ear & 60.93 & 1.83 & 9.30 & 5.78 & 7.41 \\
\hline Number of grains per spike & 93.47 & 14.00 & 32.46 & 16.30 & 16.86 \\
\hline Chlorophyll content & 87.57 & 8.74 & 19.61 & 10.17 & 10.87 \\
\hline 1000 grain wt. (g) & 67.68 & 6.19 & 15.16 & 8.94 & 10.87 \\
\hline Grain yield (g/plant) & 88.84 & 4.78 & 50.58 & 26.05 & 27.64 \\
\hline Biological yield (g/plant) & 90.39 & 7.43 & 40.74 & 20.80 & 21.88 \\
\hline
\end{tabular}

The result of analysis of heritability and genetic advance for 30 genotypes, based on 11 morphological traits and yield components showed in Table 3. Data in Table 3 revealed that, heritability estimates were highest for The Days to $50 \%$ flowering, number of productive tillers, flage leaf area, cholorophyll content, grain yield and biological yield while the plant height, spike length, no of spikelet per year and 1000 grain weight, showed moderate value for heritability. And Genetic advance estimates were highest for Flag leaf area, no. of grains per spike, and Plant height while the Chlorophyll content, Biological yield and 1000 grain weight, showed moderate value for Genetic advance, similarly Ahmad et al. $(2010)^{[16]}$ observed highest heritability for spike length $(79.35 \%)$, followed by main spike yield $(69.55 \%)$, and number of grains per spike (54.5\%); this high heritability was also associated with greater genetic advance for the above traits. Genetic advance for spike length, main spike yield, number of grains per spike was higher. Moderate to high heritability was recorded for peduncle length $(48.75 \%)$ and number of grains per spikelet (47.24\%). Monpara, $2011^{[17]}$ and Singh et al, $2012^{[18]}$ reported high range for heritability in broad sense and maximum heritability for plant height followed by number of tillers /plant, days to maturity, days to $50 \%$ flowering, harvest index, biological yield /plant,spike length, number of grains /spike, test weight (1000 grain), flag leaf length, High heritability estimates indicate that large portion of the total variance was attributed to the genotypic variance and that individual of the population differ for this trait. Wheat breeders considered heritability $\left(\mathrm{h}^{2}\right)$ estimates along with the genetic advance values because $\mathrm{h}^{2}$ alone is not good indicator of the amount of usable genetic variability (Masood et al, 1986) ${ }^{[19]}$.

In the above study 30 wheat genotypes were studied, with the 11 morphological character were influenced by environmental conditions to some extent, these character include Plant height, Days to flowering, Days to maturity, Number of productive tillers per plant, Number of spikelets per spike, Flag leaf area, Chlorophyll contents, Biological yield, Harvest index (\%), 1000-grain weight and Grain Yield per plant. These characters could be used for the estimation of variability, which describe the total number of genetic characteristics of an individual, in the genetic makeup of a species, heritability and genetic advance that describe the genetic stability performance in the individual of the population of all these factor that help genotypes to adopt environment and also help to the plant breeder, to develop the new and improved cultivar and improve the farmer's economic condition.

\section{CONCLUSIONS}

In the present study, 30 genotype of wheat were studied to Analysis of Genetic Diversity Based on Quantitative 
Characters and yield Components of Wheat (Triticum aestivum L.) Genotypes, with respect to 11 quantitative traits Days of 50\% flowering, plant height, no. of productive tillers, spike length, no. of spikelet per spike, no. of grain per spike, flag leaf area, 1000 grain weight, total grain yield per plant, biological yield per plant and chlorophyll content.

\section{Following Major Conclusions has Been Drawn from the Study}

- ANOVA indicating significant variability among the genotypes for all traits the mean sum square for 11 character were highly significant thereby the suggesting the presence of considerable amount of heritability among the 30 wheat genotypes.

- Estimation of phenotypic coefficient and phenotypic of variation and heritability showed wide range of values for the 30 genotypes for all traits and PCV and GCV were higher for many traits such as grain yield, biological yield, flag leaf area, no. of productive tiller and grain per spike.

- Heritability were estimated highest for days of 50\% flowering, no. of productive tillers, flag leaf area, chlorophyll content, grain yield and biological yield while plant height, spike length, no. of spikelet per spike and 1000 grain weight showed moderate value for heritability.

The analysis of the variability include GCV, PCV which describe the variation in the genotype that help to adopt the environment while heritability described how much variation in the phenotypic trait in a population is due to the genetic variation among individual in that population and genetic advance is the mean genotypic value of selected plant over the parental population which means the selected plant will be improved so we conclude that the estimation of the variability in the form of the GCV and PCV, heritability and genetic advance used in the crop improvement program and developed new and improved variety.

\section{Conflict of Interest}

The present study was conducted to evaluate the wheat genotypes in order to assess the presence of variability, heritability and genetic advance for desired traits and a significant amount of variation for different parameters. Good knowledge of variability heritability and genetic advance existing in different yield parameters is a pre-requisite for effective plant improvement. Improvements in crop plant through the variability and genetic advance is most important to the plant breeder foe the developments of new and developed cultivar which improve the economic condition of farmers country also.

\section{ACKNOWLEDGMENTS}

I would like thank Chaudhary Charan Singh University to giving me the opportunity to use research field, allocating the required research field supervision and thanks to all the respondents for giving me valuable information

\section{REFERENCES}

1. Baranwal, D.K, Mishra, V. K, Vishwakarma, M. K, Yadav, P. S. and B. Arun (2012). Studies on genetic variability, correlation and path analysis for yield and yield contributing traits in wheat (T. aestivum l. Em Thell.),Plant Archives,12:(1)99-104.

2. Zafarnaderi, N, Aharizad, S. And S. A. Mohammadi (2013) Relationship between grain yield and related agronomic traits in bread wheat recombinant inbred lines under water deficit condition. Ann Biol Res 4(4): 7-11.

3. O. Аremu (2012). Exploring Statistical Tools in Measuring Genetic Diversity for Crop Improvement, Genetic Diversity in Plants, Prof. Mahmut Caliskan (Ed.), and ISBN: 978-953-51-0185-7. 
4. Saleem, B, Khan, A. S, Shahzad, M. T. and F. Ijaz(2016) ESTIMATION OF HERITABILITY AND GENETIC ADVANCE FOR VARIOUS METRIC TRAITS IN SEVEN F2 POPULATIONS OF BREAD WHEAT (TRITICUM AESTIVUM L.), J. Agri. Sci, 61( 1$): 1-9$

5. Memon, S. M, Qureshi, M. U, Ansari, B. A. and M.A. Sial (2007). Genetic heritability for grain yield and its related character in spring wheat. Pak. J. Bot, 39(5): 1503-1509.

6. Mangi, S.A, Sial, M.A, Ansari, B.A. and M.A Arain (2008). Study of genetic parameters in segregating populations of spring wheat. Pak. J. Bot, 39(7): 2407-2413.

7. Waqar-ul-haq, Malik, M.F, Rashid, M, Munir, M. and Z. Akram (2008). Evaluation and estimation of heritability and genetic advancement for yield related attributes in wheat lines. Pak. J. Bot, 40(4): 1699-1702.

8. Hanson CH, Rabinson HE, Comstock RE (1956) Biometrical studies of yield is segregating population of Korean lespedeza. Agron J 48 : 268-272.

9. Johnson HW, Robinson HF, Comstock RE (1956) Genotypic and phenotypic correlations and their implication in selection. Agron J, 47: 477-483.

10. Abinasa M, Ayana, A. And G. Bultosa (2011). Genetic variability, heritability and trait associations in durum wheat (TriticumturgidumL. var. durum) genotypes. Afr. J. Agric. Res, 6 (17): 3972 - 3979.

11. Alam, M.A, Khan, A.A, Alam, M.K, Sarker, Z.I. and M.M. Rahman (2013). Variability and diversity studies in durum wheat (triticum durum). J. of Sci. and Technol, 1 - 5.

12. Kyosev and Desheva (2015) Study on variability, heritability, genetic advance and associations among characters in emmer wheat genotypes (Triticum dicoccon Schrank).J. BioSci. Biotechnol:221-228.

13. Wolde, T, Eticha' F, Alamerew, S, Assefa, E. and D, Dutamo (2016). Genetic variability, heritability and genetic advance for yield and yield related traits in Durum wheat (Triticum durum L.) accessions, J. Agri. Res, 5(3): 042 - 047.

14. Wahidy, S, Suresh, B.G. and GR Lavanya (2016). Genetic variability, correlation and path analysis in wheat germplasm (Triticum aestivum L.).Inter. J. Multidisciplinary Res. Develop. 3(7); 24-27

15. Kumar, J, Kumar, M, Singh, S.K. and L. Singh (2017). Estimation of Genetic Variability and Heritability in Bread Wheat under Abiotic Stress, Int. J. Pure App. Biosci. 5(1): 156-163

16. Ahmad, K.L, Sail, M.A, Arain, M.A, Mirbahari, A.A, Pirzada, A.J, Dahot, M.U. and S.M. Mangrio (2010). Heritability studies of yield and yield associated traits in bread wheat, Pak. J.bot, 42(1):111-115

17. Monpara BA(2011).Grain filling period as a measure of yield improvement in bread wheat. Crop Improvement. 38(1):1-9.

18. Singh, A.K, Singh, S.B, Singh, A.P. and A.K. (2012). Sharma Genetic variability, character association and path analysis for seed yield and its component characters in wheat (Triticum aestivum L.) under rainfed environment. Ind. J. Agri. Res, 46(1):48-53.

19. Masood,M.S, Mujahid, M.V, Kisana, N.S. and N.I. Hasmi (1986). Genetic variability in wheat under rainfed condition. Pak. J. Agri. Sci. 7: 244-246 
